\title{
Creasable Batteries: Understanding Failure Modes through Dynamic Electrochemical Mechanical Testing
}

Aaron J. Blake,,$^{\dagger \dagger,}$ Ryan R. Kohlmeyer, ${ }^{\S, \dagger}{ }^{\dagger} *$ Lawrence F. Drummy, ${ }^{\dagger}$ Jacob S.

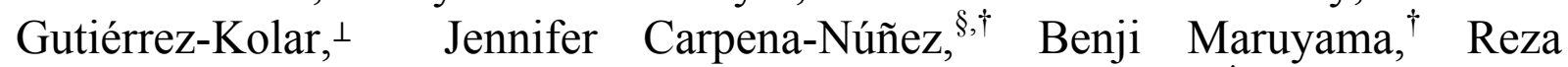

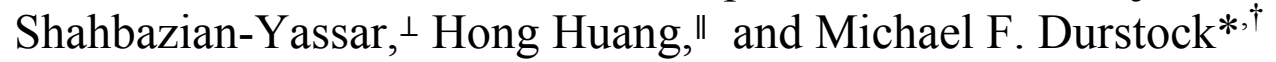

${ }^{\dagger}$ Soft Materials Branch, Materials and Manufacturing Directorate, Air Force Research Laboratory, Wright Patterson Air Force Base, Ohio 45433, United States

${ }^{\S}$ National Research Council, Washington, D.C. 20001, United States

"Department of Mechanical and Materials Engineering, Wright State University, Dayton, Ohio 45435, United States

${ }^{\perp}$ Department of Mechanical Engineering-Engineering Mechanics, Michigan Technological University, Houghton, Michigan 49931, United States

*michael.durstock@us.af.mil

*ryan.kohlmeyer.ctr@us.af.mil 


\section{Additional Materials \& Methods}

A nonwoven multiwalled carbon nanotube (MWNT) mat (Nanocomp Technologies, Inc., Merrimack, NH) was used as received. Traditional $\mathrm{Cu}$ (EQ-bccf-25u) or Al (EQ-bcaf15u-280) foil current collectors (CCs) were purchased from the MTI Corporation. Spinel lithium titanate $\left(\mathrm{Li}_{4} \mathrm{Ti}_{5} \mathrm{O}_{12}\right)$ nanopowder, polyvinyldene fluoride (PVDF), and 1-methyl-2pyrrolidone (NMP) were purchased from Sigma Aldrich. Lithium iron phosphate $\left(\mathrm{LiFePO}_{4}\right)$ was purchased through BASF (HED LFP-400) and graphite was purchased from Asbury Graphite Mills (HPM 850 powder). $1 \mathrm{M} \mathrm{LiPF}_{6}$ in 1:2 ethylene carbonate:diethyl carbonate was used as received from Novolyte Technologies Inc. For the electrolyte wetting experiment in Figure S4, samples were taped to a glass slide and $2.0 \mu \mathrm{L}$ of liquid electrolyte was applied to the center of each sample with a micropipetter. Photos were taken on the top side and bottom side (photo taken through glass substrate) after letting electrolyte sit on the samples for $5 \mathrm{~min}$.

\section{Additional Sample Characterization}

High Angle Annular Dark Field Scanning Transmission Electron Microscopy (HAADF-STEM) was used to collect a tomographic tilt series. Due to sample geometry constraints, tilt ranges varied from \pm 70 degrees down to \pm 50 degrees. After alignment using cross-correlation, Model Based Iterative Reconstruction (MBIR) was used to reconstruct the raw tilt series into a three dimensional volume. MBIR shows significantly reduced missing wedge artifacts, even down to limited tilt ranges of \pm 30 degrees, and so the reconstructions for the \pm 50 degree tilt series showed minimal artifacts. The volume was segmented and visualized in Avizo Fire 7. The low degree of noise in MBIR reconstructions allow for a simple threshold-based segmentation of the MWNT web and the iron catalyst (Figure S2).

\section{Fabrication and Test of Flexible Li-ion Batteries}

Flexible Li-ion batteries were prepared by cutting all of the battery components and encapsulating them together between two layers of $75 \mu \mathrm{m}$ thick Surlyn (GLTE/M, Europack, Inc.). The electrodes were cut to $3 \times 3 \mathrm{~cm}^{2}$ with electrical lead dimensions of approximately 1 x $2 \mathrm{~cm}^{2}$. The actual anode capacity/cathode capacity ratio was adjusted between $0.80-0.90$ for the $\mathrm{Li}_{4} \mathrm{Ti}_{5} \mathrm{O}_{12} / / \mathrm{LiFePO}_{4}$ full-cells. The Celgard 2325 separator was cut to $4 \times 5 \mathrm{~cm}^{2}$. Cu wires were placed in contact with the electrical leads of the electrodes with the remainder of the wire left outside of the encapsulation layers. Initially, a portion of the $\mathrm{Cu}$ wire leads were laminated between two sheets of $75 \mu \mathrm{m}$ Surlyn using a GBC 9" Personal Desktop Laminator to prevent electrolyte leakage. The perimeter of the flex-cell was sealed using a Ziploc ${ }^{\circledR} \mathrm{V} 151$ vacuum sealer system. Sealing was performed between two non-porous Teflon sheets to prevent sticking to the heating element. Using a needle, $0.8 \mathrm{~mL}$ of liquid electrolyte was added to the battery in an argon glovebox, and then the excess region of the cell was sealed off using the same method as described above (Figure S7). To create better contact between all of the layers, the entire battery was carefully kneaded to ensure electrolyte uptake and to remove any bubbles.

A custom-built rolling instrument was used for in situ analyses, in which the electrochemical performances of the flexible Li-ion batteries were assessed under repeated mechanical deformation. Bending conditions were chosen such that the strain, $\varepsilon$, experienced by the battery ranged from $2.1 \%(r=7.88 \mathrm{~mm})$ to $2.6 \%(r=6.35 \mathrm{~mm})$ to $4.2 \%(r=4.00 \mathrm{~mm})$ according to 
$\varepsilon_{T}=-\varepsilon_{C}=\frac{y}{r}$

where $y$ is the distance from the surface of the flex-cell to its neutral plane, and $r$ is the mandrel radius. Given that the total thickness of the flex-cell was only ca. $335 \mu \mathrm{m}$, shifting of the neutral axis could be neglected, and its location was taken to be the middle layer of the flex-cell (i.e., the separator). Therefore the tensile, $T$, and compressive, $C$, strains are equal in magnitude, but opposite in direction. A pure-bending set-up and linear strain field were assumed for the above calculations.

The flexible Li-ion batteries with dimensions of approximately $12 \times 8 \mathrm{~cm}^{2}$ were adhered to each mandrel using double sided tape. Two $1.0 \times 7.6 \mathrm{~cm}^{2}$ (400 $\mu \mathrm{m}$ thick) polydimethylsiloxane (Sylgard 184, Dow Corning) strips were placed at each side of the flexible battery to increase the friction between the rolling mandrel and the moving stage. For automated testing, each mandrel was rolled a distance of $3 \mathrm{~cm}$ over the electrodes at a linear velocity of $10 \mathrm{~mm} \mathrm{sec}^{-1}$ using Motion Planner v4.3.2 software. Each cycle (roll/unroll) took 6 sec. for completion. The electrochemical properties were galvanostatically tested in the fullcell potential range of 1.2-2.4 V. Each cell was first charged in argon environment to $2.4 \mathrm{~V}$ at a $\mathrm{C} / 3$ current rate. The bend test was then performed in ambient conditions while the cell was discharged at a $\mathrm{C} / 5$ current rate (calculated using the active mass of $\mathrm{Li}_{4} \mathrm{Ti}_{5} \mathrm{O}_{12}$ ). Every 20 min. the mandrel was replaced with one of a smaller radius of curvature. During the fold test in Figure 5, each battery was discharged at a $\mathrm{C} / 5$ current rate and subjected to $\pm 180^{\circ}$ folds every $20 \mathrm{sec}$. for the duration of the test. During the fold test in Figure S7 and Video S4, the cell was discharged at a $\mathrm{C} / 5$ current rate and subjected to two fold cycles consisting of 4 folding patterns, with 5 min. of rest between each cycle. For all of the in situ mechanical tests using MWNT mat full-cells, it is worth mentioning that air and moisture permeability of the Surlyn encapsulant limited the duration of the test, not mechanical insult as in the case of devices fabricated with metal foil CCs.
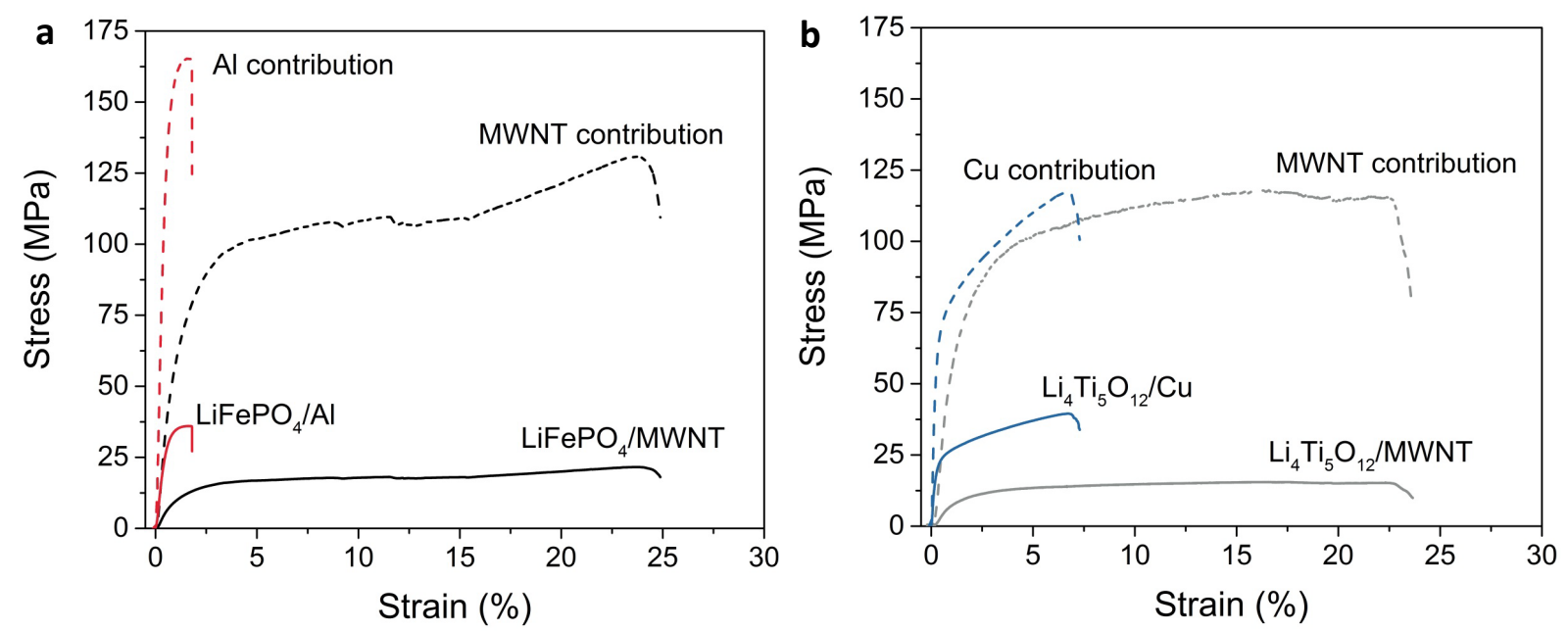

Figure S1. Mechanical characterization on CCs with electrode coatings. Uniaxial tensile stress-strain curves of (a) $\mathrm{LiFePO}_{4}$ on $\mathrm{Al}$ and MWNT mat, and (b) $\mathrm{Li}_{4} \mathrm{Ti}_{5} \mathrm{O}_{12}$ on $\mathrm{Cu}$ and MWNT mat. The solid traces indicate the stress calculated using the specimen width and total thickness (coating plus CC), while the dashed traces indicate the stress calculated using the specimen width and CC thickness only. The latter allows comparison to the uncoated CCs in Figure $1 \mathrm{~b}$. The stress relief observed in the plastic region of the stress-strain curves for both $\mathrm{LiFePO} / \mathrm{MWNT}$ and $\mathrm{Li}_{4} \mathrm{Ti}_{5} \mathrm{O}_{12} / \mathrm{MWNT}$ resulted from localized fracturing of the active material as the MWNT mat elongated. 


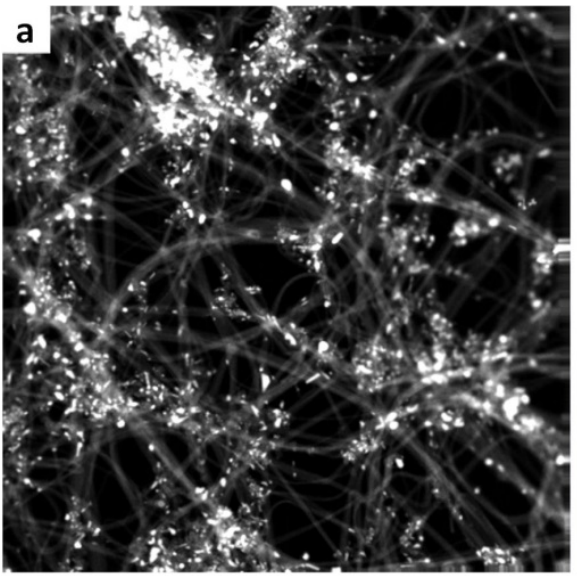

$300 \mathrm{~nm}$

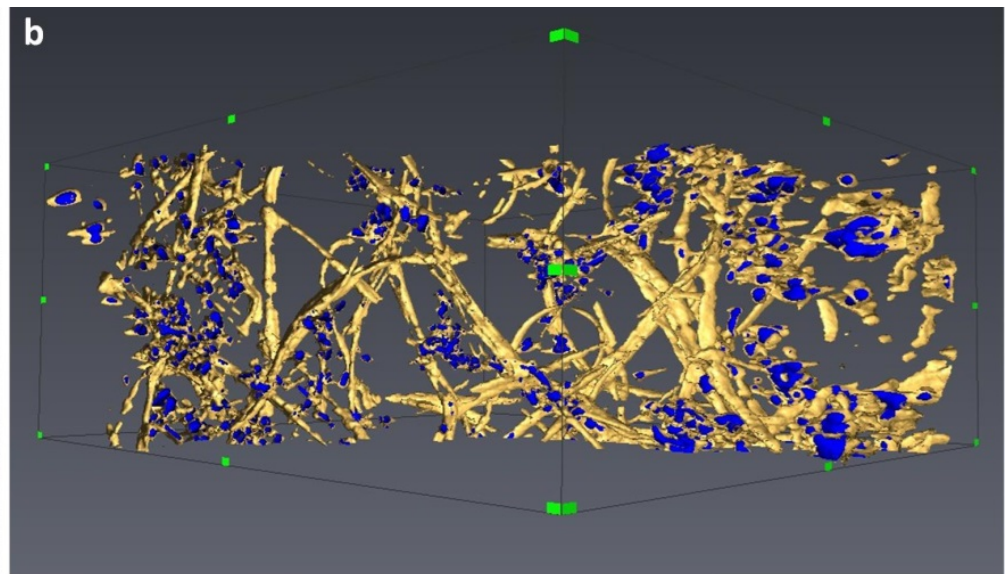

MWNT $\square$ Iron Catalyst

Figure S2. HAADF-STEM tomography on scotch tape exfoliated MWNT mat. (a) 0 degree HAADF-STEM image from the tilt series. (b) MBIR reconstruction visualized in Avizo Fire with MWNTs in gold and catalyst in blue. Corresponding 3D rotational videos of $(a, b)$ can be seen in Video S3.

\section{Pristine MWNT mat}

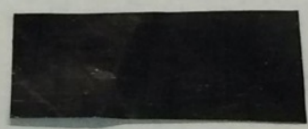

3. Peel

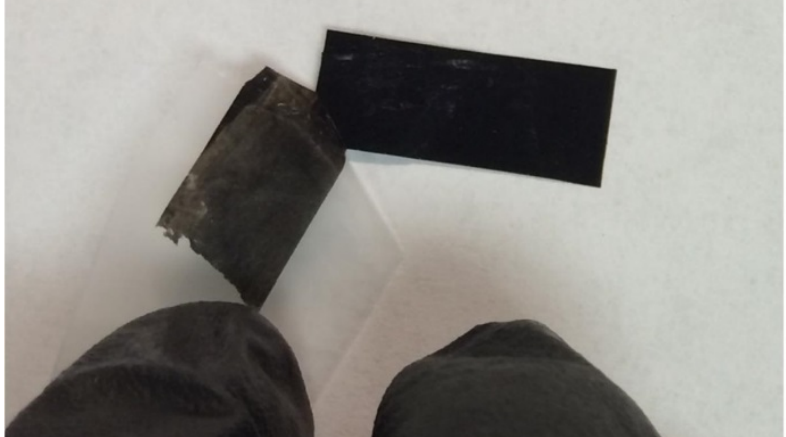

\section{Adhere Tape}
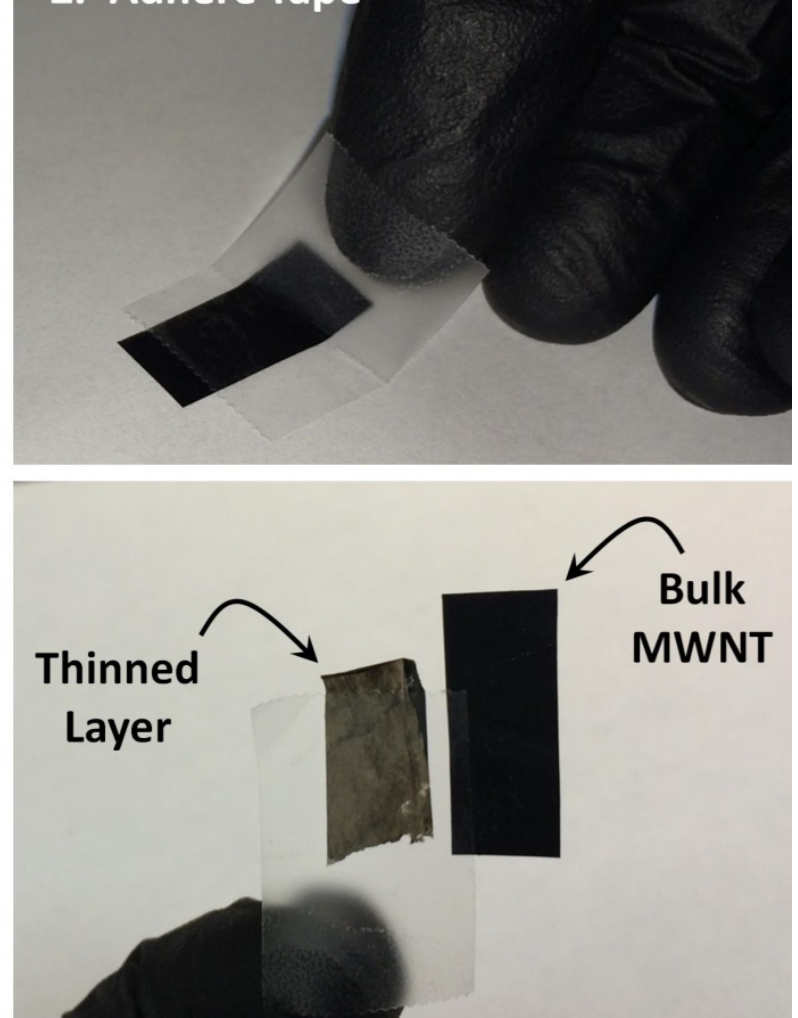

Figure S3. Scotch tape exfoliation of a MWNT mat for TEM microscopy. 


\section{Top Side}

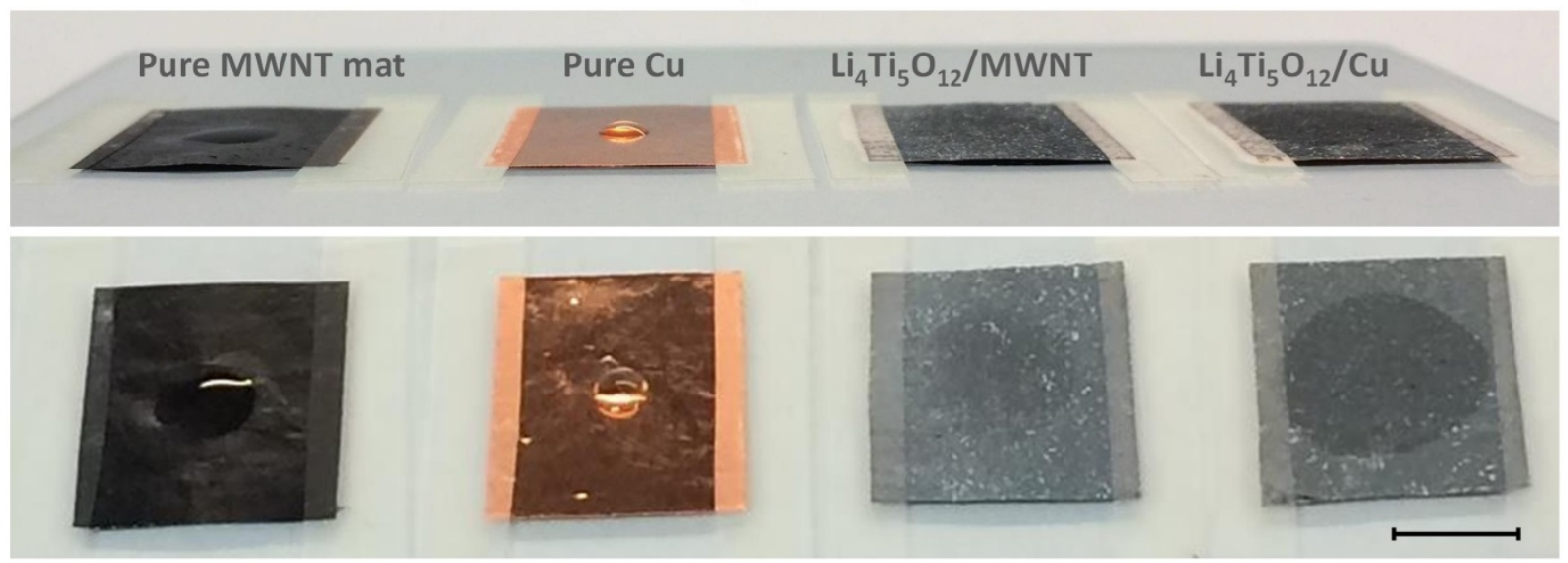

Bottom Side

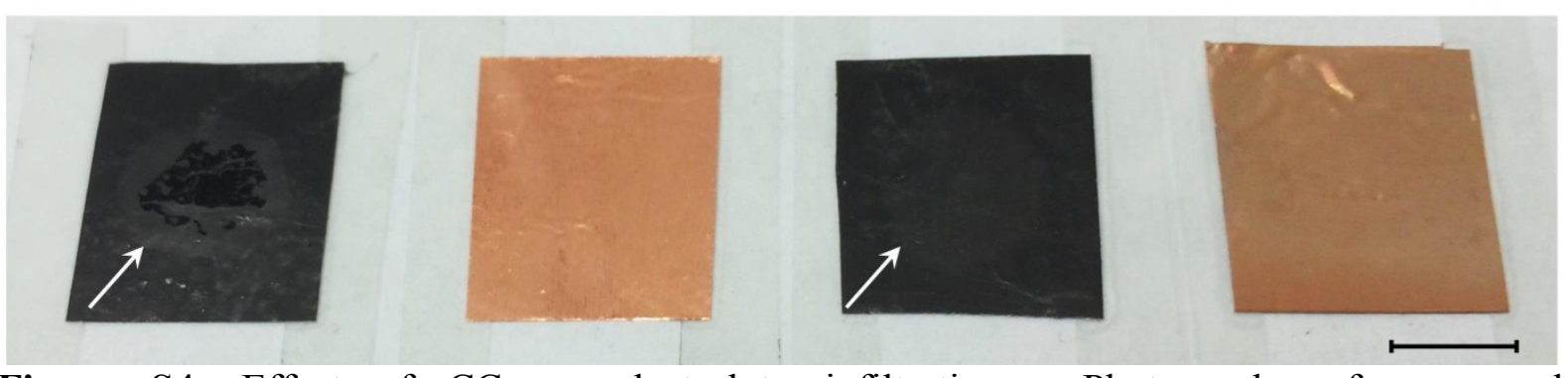

Figure S4. Effect of $\mathrm{CC}$ on electrolyte infiltration. Photographs of pure and $\mathrm{Li}_{4} \mathrm{Ti}_{5} \mathrm{O}_{12} / \mathrm{MWNT}$ and $\mathrm{Li}_{4} \mathrm{Ti}_{5} \mathrm{O}_{12} / \mathrm{Cu}$ after spotting with $2.0 \mu \mathrm{L}$ of liquid electrolyte $(1 \mathrm{M}$ $\mathrm{LiPF}_{6}$ in 1:2 ethylene carbonate:diethyl carbonate). White arrows in the photograph of the bottom side indicate the edge of the electrolyte spot. Scale bars: $0.5 \mathrm{~cm}$.

Figure S4 shows the difference in liquid electrolyte wetting between the MWNT mat and a $\mathrm{Cu}$ foil $\mathrm{CC}$. On both active material-coated and neat $\mathrm{CCs}$, a $2 \mu \mathrm{L}$ electrolyte drop quickly wicks through the MWNT mat and is visible on the bottom side of the film. On the contrary, electrolyte cannot travel through the thickness of the $\mathrm{Cu}$ foil. Additionally, there is a significantly lower contact angle in the neat mat vs. the neat $\mathrm{Cu}$ foil, indicating better wettability in the nanotube sample. This result is consistent with Wang et al. who found better wetting of droplets of active material slurry on a CNT film vs. a $\mathrm{Cu}$ foil. ${ }^{1}$ 


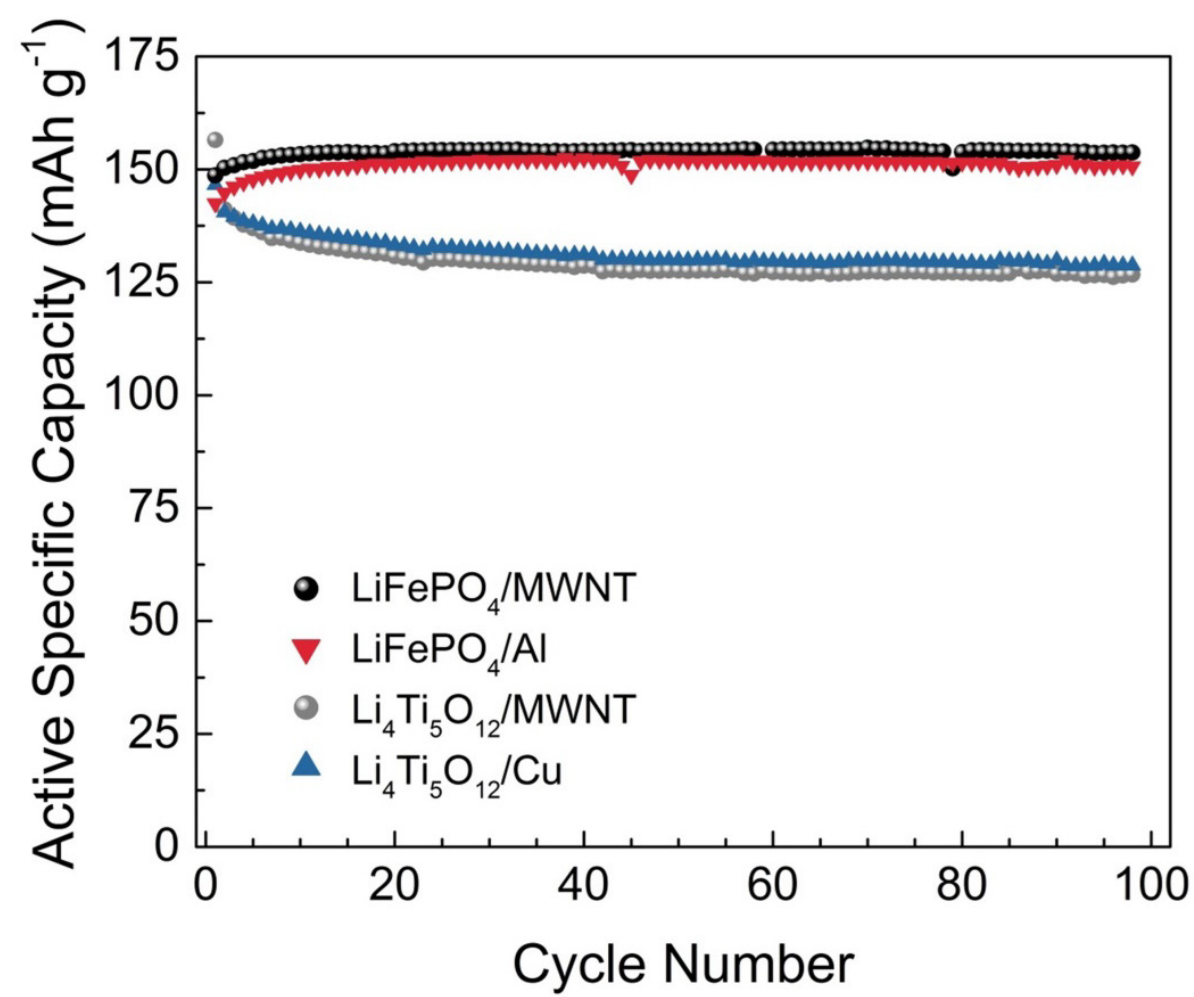

Figure S5. Cycling performances $(\mathrm{C} / 5)$ of $\mathrm{LiFePO}_{4}$ and $\mathrm{Li}_{4} \mathrm{Ti}_{5} \mathrm{O}_{12}$ on metal foil and MWNT CCs, normalized by active mass.

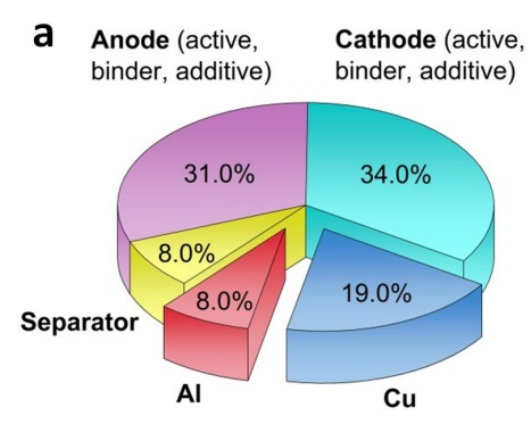

Commercial - Metal Foil

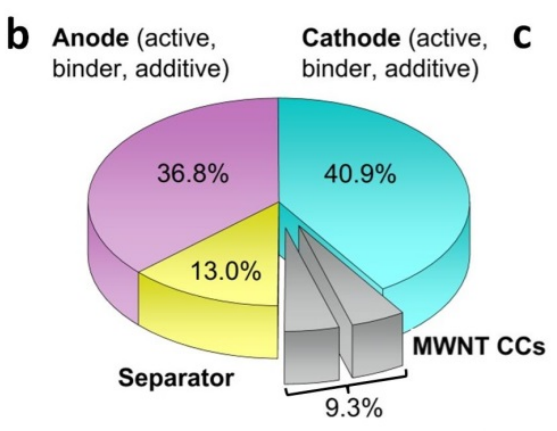

MWNT (Single-Sided Coating)

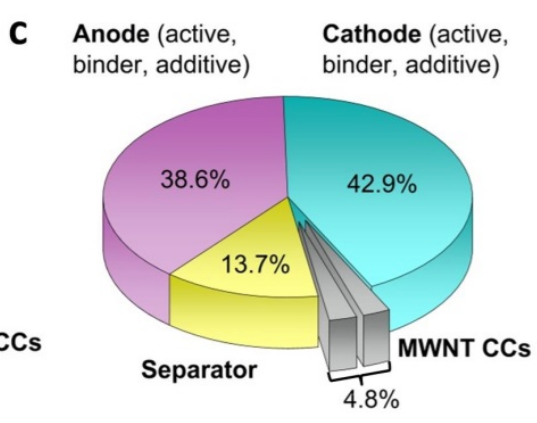

MWNT (Double-Sided Coating)

Figure S6. Full-cell mass distributions. Mass distribution of the main components for (a) a typical commercial full-cell, ${ }^{2}$ and for $(b, c)$ a MWNT-based full-cell with active material on (b) one side of the $\mathrm{CC}$ or (c) on both sides of the CC. The mass distribution of the electrolyte and encapsulation were left out for simplicity. 


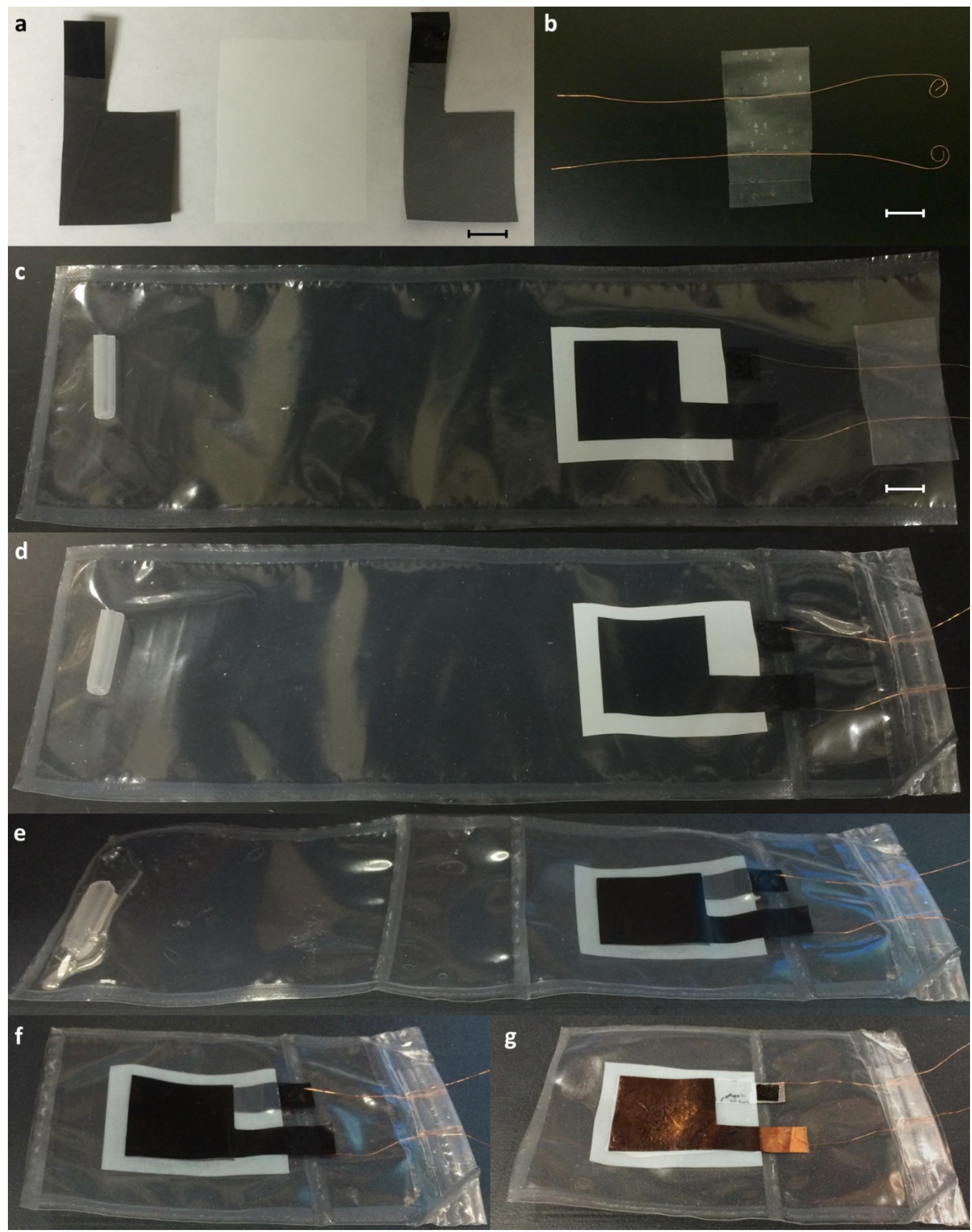

Figure S7. Photographs of the process of fabricating Surlyn-encapsulated flexible full-cells. (a) $\mathrm{LiFePO}_{4} / \mathrm{MWNT}$ (left) and $\mathrm{Li}_{4} \mathrm{Ti}_{5} \mathrm{O}_{12} / \mathrm{MWNT}$ (right) electrodes and separator membrane (center). (b) Wire leads thermally laminated between two pieces of $75 \mu \mathrm{m}$ Surlyn. (c) $75 \mu \mathrm{m}$ Surlyn pouch thermally sealed on three edges containing the electrodes, separator, and wire leads. A needle cap is contained in the opposite side of the pouch. (d) Pouch after thermally sealing the final edge after folding. An additional seal was placed at the nanotube electrode leads. (e) Pouch after addition of $0.8 \mathrm{~mL}$ liquid electrolyte (punctured pouch at the needle cap). Bubbles were kneaded away from the battery and sealed (middle of the pouch). A final seal was done closer to the battery to remove new bubbles after the first charge. (f) Sealed flexible battery used for in situ mechanical testing after cutting away the excess Surlyn. (g) Metal foil full-cell in a Surlyn pouch made using the same procedure shown in (a-f). Scale bars: $1.0 \mathrm{~cm}$ 


\begin{tabular}{|c|c|c|c|}
\hline$r(\mathbf{m m})$ & $\mathbf{R M S E}_{\text {MWNT }}(\mathbf{V})$ & $\mathbf{R M S E}_{\text {Foil }}(\mathbf{V})$ & $\frac{\text { RMSE }_{\text {Foil }}}{\mathbf{R M S E}_{\mathbf{M W N T}}}$ \\
\hline$\infty$ & $2.51 \mathrm{E}-04$ & $2.00 \mathrm{E}-04$ & 0.80 \\
7.88 & $4.88 \mathrm{E}-04$ & $1.26 \mathrm{E}-03$ & 2.58 \\
6.35 & $5.09 \mathrm{E}-04$ & $5.55 \mathrm{E}-03$ & 10.90 \\
4.00 & $8.40 \mathrm{E}-04$ & $1.18 \mathrm{E}-02$ & 14.05 \\
\hline
\end{tabular}

Table S1. Analysis of voltage fluctuation during in situ bending. Root mean square error (RMSE) calculated from the fluctuation associated with the insets of Figure $4 \mathrm{~d}$ and the unstrained state $(r=\infty)$. Ratios between the strained and unstrained-states were used to quantify the amount of fluctuation observed at each mandrel radius. To negate the effect of voltage drift, a linear trendline was subtracted from each dataset, then the RMSE was calculated by:

$\mathrm{RMSE}=\sqrt{\frac{1}{\mathrm{n}} \sum_{\mathrm{i}=1}^{\mathrm{n}}\left(\mathrm{V}_{\mathrm{i}}-\widehat{\mathrm{V}}_{\mathrm{i}}\right)^{2}}$

where $n$ was the number of data points, $V_{i}$ was the observed voltage, and the predicted voltage $\left(\widehat{V}_{i}\right)$ was taken as the root mean square (RMS) of the unstrained data:

$\mathrm{RMS}=\sqrt{\frac{1}{\mathrm{n}} \sum_{\mathrm{i}=1}^{\mathrm{n}} \mathrm{V}_{\mathrm{i}}^{2}}$ 

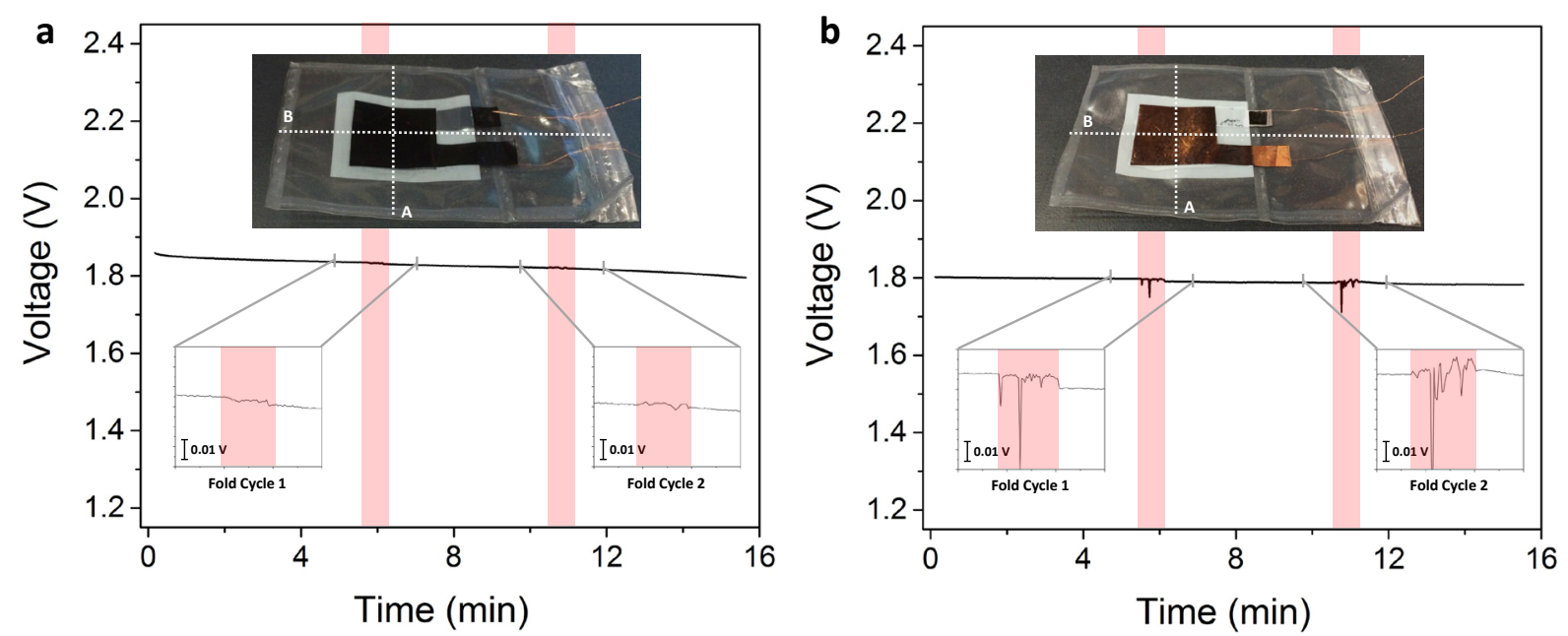

C

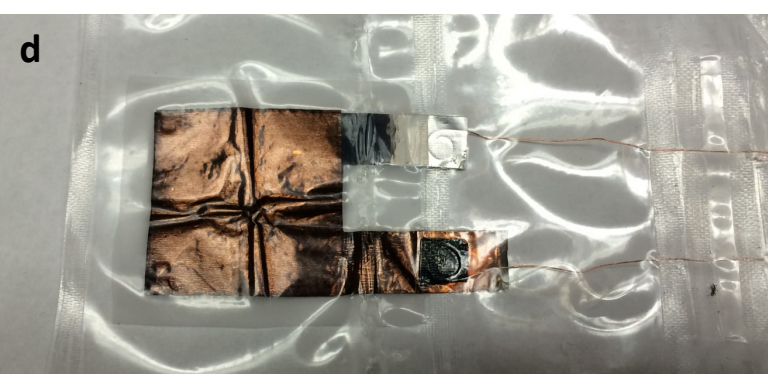

Figure S8. In situ folding of MWNT mat and metal foil $\mathrm{LiFePO}_{4} / / \mathrm{Li}_{4} \mathrm{Ti}_{5} \mathrm{O}_{12}$ full-cells. Discharge plateau of (a) nanotube and (b) metal foil full-cells at a $\mathrm{C} / 5$ current rate during the fold test. Each battery was subjected to 2 fold cycles that are indicated in light red. Each fold cycle consists of four folds, $\pm 180^{\circ}$ about line A, followed by $\pm 180^{\circ}$ about line B as shown in the figure insets. Photographs of (c) a MWNT mat and (d) a metal foil full-cell after three fold cycles.

In a separate test, each full-cell was subjected to two fold cycles consisting of sequential $\pm 180^{\circ}$ folding about two perpendicular lines. An entire fold cycle can be seen for both MWNT and foil full-cells in Video S4. The electrochemical performance of the MWNT full-cell remained nearly unaffected throughout the fold cycles (Figure S8a), whereas the metal foil full-cell again experienced appreciable voltage fluctuations during the same mechanical deformation (Figure S8b). After several fold cycles, macroscopic irreversible buckling can be observed along both folding axes in the metal foil full-cell, whereas little to no folding-induced damage or crease memory can be seen in the MWNT CCs (Figure S8c,d). 


\section{References}

(1) Wang, K.; Luo, S.; Wu, Y.; He, X.; Zhao, F.; Wang, J.; Jiang, K.; Fan, S. SuperAligned Carbon Nanotube Films as Current Collectors for Lightweight and Flexible Lithium Ion Batteries. Adv. Funct. Mater. 2013, 23, 846-853.

(2) Johnson, B. A.; White, R. E. Characterization of Commercially Available Lithium-Ion Batteries. J. Power Sources 1998, 70, 48-54. 